\title{
Effect of Solcoseryl in Corneal Alkali Burn Rat Model
}

\author{
Hoon Kim \\ Hong-Bee Kim \\ Jae-Hwi Seo \\ Dong Cho Lee \\ Kyong Jin Cho
}

Department of Ophthalmology, Dankook University College of Medicine, Cheonan, Korea
Received November 27, 2020

Accepted February 19, 2021

\footnotetext{
Correspondence

Kyong-Jin Cho

Department of Ophthalmology, Dankook

University College of Medicine, 119 Dandae-ro,

Dongnam-gu, Cheonan 31116, Korea

Tel.: +82-41-550-3945

Fax: +82-41-561-0137

E-mail: perfectcuredahanmail.net

(C) Korean Society for Laser Medicine and Surgery

(c) This is an open access article distributed under the terms of the Creative Commons Attribution NonCommercial License (http://creativecommons.org/ licenses/by-nc/4.0) which permits unrestricted noncommercial use, distribution, and reproduction in any medium, provided the original work is properly cited.
}

\author{
Background and Objectives \\ Ocular alkali burns cause severe damage to the ocular tissues and vision \\ loss. Solcoseryl is a standardized calf blood extract that normalizes the \\ metabolic disturbance and aids in maintaining the chemical and \\ hormonal balance and has been used to treat burns in various tissues. \\ This study examined the effects of Solcoseryl on a rat corneal alkali burn \\ model.
}

\section{Materials and Methods}

Twenty rats were assigned randomly to four equal groups, including alkali burn, hyaluronic acid, Solcoseryl eyedrop, and Solcoseryl gel. A corneal alkali burn was induced by a $\mathrm{NaOH}$-soaked paper disc. The treatments were given twice a day, every day. The wound area was measured after 24 and 48 hours, and the degree of neovascularization and corneal opacity were scored every week. The rats were sacrificed after three weeks for immunohistochemistry $(\mathrm{IHC})$ to compare the level of inflammatory cytokines, IL-1 $\beta, I L-6$, and TNF- $\alpha$. The thickness of the retinal layers was compared to observe any changes in the retina.

\section{Results}

The use of Solcoseryl on corneal alkali burn accelerated wound healing with less neovascularization, greater opacity, and less cataract. IHC showed that the inflammation of the cornea was controlled by both the hyaluronic acid and Solcoseryl treatments. On the other hand, the inflammation had spread to the retina. When the dosage forms were compared, eyedrops were more effective on corneal inflammation, while the gel-type had a greater effect on retinal inflammation.

\section{Conclusion}

Solcoseryl was effective in accelerating the wound healing rate on a corneal alkali burn but could not prevent the spread of inflammation from the cornea to the retina. Eyedrops were more effective on inflammation in the cornea, and the gel was more effective in the retina.

\section{Key words}

Corneal burn; Alkali burn; In vivo; Solcoseryl; Inflammation 


\section{INTRODUCTION}

Corneal blindness, being the fourth leading cause of blindness globally, is one of the major causes of visual deficiency after cataract, glaucoma, and macular degeneration. ' Corneal blindness may be caused by diseases or injuries, while corneal injuries contribute to blindness with about 2 million new cases of unilateral blindness annually. ${ }^{2}$

Especially, ocular burns constitute true ocular emergencies and both thermal and chemical burns represent potentially blinding ocular injuries. Chemical burns are caused by either alkaline or acidic agents, and alkaline agents are known to cause more severe damage than acidic agents since they have both hydrophilic and lipophilic properties, which allow them to penetrate cell membranes and enter the anterior chamber. Acidic agents cause less damage because many corneal proteins bound to acid serve as a chemical buffer and coagulated tissues act as a barrier which blocks further penetration of acid. ${ }^{3}$

When corneal alkali burn occurs, it is graded based on injured area, penetrated depth, and the characteristics of chemical agent exposed. As a first aid, immediate wash out using water, saline, or balanced salt solution must be performed, then appropriate treatments follow depending on the grades. Although surgical means are required in case of severe corneal burns, drugs and topical agents may also be prescribed to accelerate epithelial growth and cellular proliferation, to minimize ulcer formation, or to control inflammation.

Solcoseryl ${ }^{\circledR}$ is a chemically and biologically standardized protein free non-antigenic and non-pyrogenic dialysate of blood from healthy veal calves, developed as a result of the search for humoral factors controlling growth. It contains a broad spectrum of low molecular organic and inorganic substances which help in wound healing by normalizing metabolic disturbance and tissue damage associated with stress injury and hypoxia. It was well known that use of Solcoseryl reduces scarring and inflammation and accelerates wound healing by balancing cellular and hormonal reactions in various tissues, ${ }^{4}$ and such balance is crucial in recovery from alkali burn.

In the current study, we aimed to observe and confirm the effect of two commercially available Solcoseryl types in vivo on the corneal alkali burn rat model.

\section{MATERIALS AND METHODS}

\section{Animals}

The study was approved by the Dankook University Medical School Research Instituitional Animal Care and Use Committee (DKU-21-002), and conducted on 6-week old SD rats (OrientBio, Seongnam, Korea). Animals were housed and maintained at the Laboratory Animal Unit of the Dankook University. All animals were treated in accordance with the Association for Research in Vision and Ophthalmology (ARVO) statement for the use of animals in ophthalmic and vision research. A total of 20 rats were randomly assigned to four equal groups according to the treatment plans as follows: (1) control group with corneal alkali burn with no treatment; (2) corneal alkali burn with hyaluronic acid treatment, (3) corneal alkali burn with Solcoseryl eyedrop treatment; and (4) corneal alkali burn with Solcoseryl gel treatment.

\section{Corneal alkali burn induction}

Corneal alkali burn was induced in all the experimental groups, by placing a 3.5-mm paper disc soaked in $1 \mathrm{~N}$ $\mathrm{NaOH}$ on the center of cornea for 30 seconds. Cornea was washed right after removing the paper disc with 10 $\mathrm{mL}$ phosphate buffered saline thoroughly.

\section{Hyaluronic acid and Solcoseryl treatments}

Hyaluronic acid (Kynex ${ }^{\circledR}$; Alcon, Seoul, Koreal and Solcoseryl (Solcorin ${ }^{\circledR}$ eyedrop and ophthalmic gel; Hanlim Pharm. Co., Seoul, Koreal treatments were given to the rats twice a day for three weeks of experiment period. A single drop (approximately $40 \mu \mathrm{L}$ ) was given at a time.

\section{Ocular sign assessment}

Cataract scores, neovascularization and corneal opacity scores were measured every week. Neovascularization scores were given to each corneal quadrant between 0 to 3 based on the centripetal extent of the neovascular branches from the limbus. Scores of each quadrant were summed ranging 0 to 12 for each eye. ${ }^{5}$ Corneal opacity was graded on a numerical scale of 0 to $4-0$, clear cornea; 1, mild stromal opacity; 2 , moderate stromal opacity; 3 , severe corneal opacity with visible iris; 4 , opaque cornea with iris not visible. ${ }^{6}$ Cataract scores were not given to the eyes with corneal opacity scores of 4.

\section{Tissue collection for histological analysis}

Eye and eyelid tissues including the nasal, central and temporal potion of the eye and eyeball were excised after $\mathrm{CO}_{2}$ euthanasia on day 21. The tissues were fixed with $4 \%$ 
paraformaldehyde, embedded in OCT compound (TissueTek $^{\circledR}$, Sakura, Japan), and vertically cut into $15-\mu m$-thick sections. The sections were stained with hematoxylin and eosin for light microscopic examination.

\section{Immunohistochemistry}

For immunohistochemistry, inflammatory cytokines interleukin-1 beta (IL-1B; ab9722; Abcam, Cambridge, MA, USA), interleukin-6 (IL-6; ab208113; Abcam) and tumor necrosis factor-alpha (TNF- $\alpha$; ab6671; Abcam) were used to assess the level of inflammation in the collected tissues ${ }^{7}$.

\section{Statistical Analysis}

The data were analyzed using GraphPad Prism (GraphPad, San Diego, CA, USAl and are expressed as the mean \pm standard deviation of the mean. The differences between the groups were analyzed using one-way analysis of variance (ANOVA), and statistical significance was defined as $p<0.05$ using Tukey's test.

\section{RESULTS}

Observations under brightfield and blue lights showed that corneal alkali burn was successfully induced in all the groups, with the center of cornea being melt in uniform sizes (Fig. 1). When the rates of wound healing were compared in all the groups, treatment groups had faster healing rate compared to the control group. Solcoseryl gel treatment group showed the fastest healing rate in all groups, and followed by hyaluronic acid and Solcoseryl eyedrop treatment groups (Fig. 2).

Neovascularization and corneal opacity scores were given every week at day 8, 15, 22 (Fig. 3, 4). Neovascularization scores in Solcoseryl gel treatment group showed a tendency to be lower than the control group every week, while hyaluronic acid treatment group had higher scores than the control every week. Solcoseryl eyedrop treatment group had higher scores in week 1 and 2, then score lowered down in the third week (Fig. 3). Corneal opacity results appeared to be similar with neovascularization scores: Solcoseryl gel treatment group being the lowest, Solcoseryl eyedrop treatment group being higher in the first two weeks and lower in third week compared to the control, hyaluronic acid treatment group being higher than the control group in all weeks (Fig. 4).

Weekly cataract scores in all groups were compared in this study, and the results showed that percentages of opaque cornea with iris not visible lgrade not applicable; $\mathrm{N} / \mathrm{Al}$ in the control and hyaluronic acid treatment groups were higher than Solcoseryl eyedrop and gel treatment groups, while ratio of less severe cataract were higher in Solcoseryl treatment groups (Fig. 5).

Histological analysis showed that corneal structures were more stable in Solcoseryl treatment groups, while bodily fluid accumulated in stroma was observed in hyal-
A Control

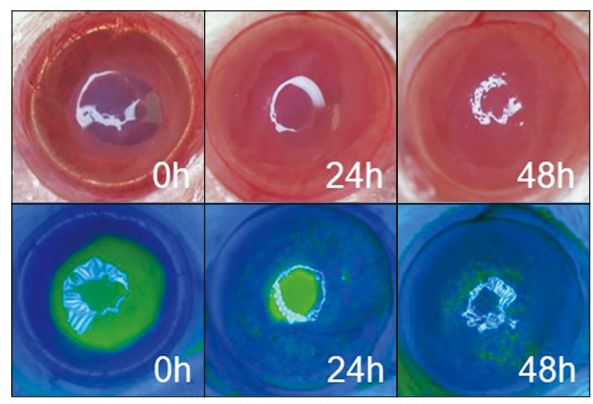

C Solcoseryl (eyedrop)

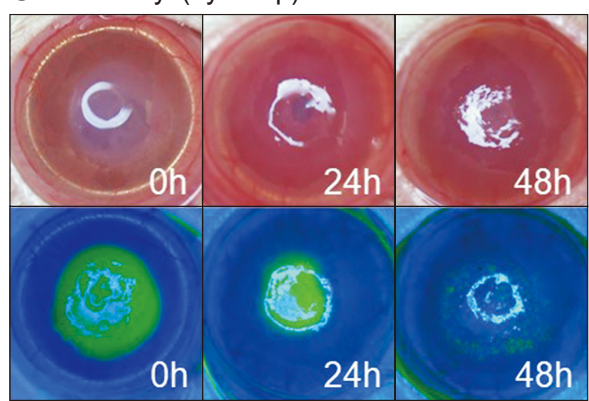

B Hyaluronic acid

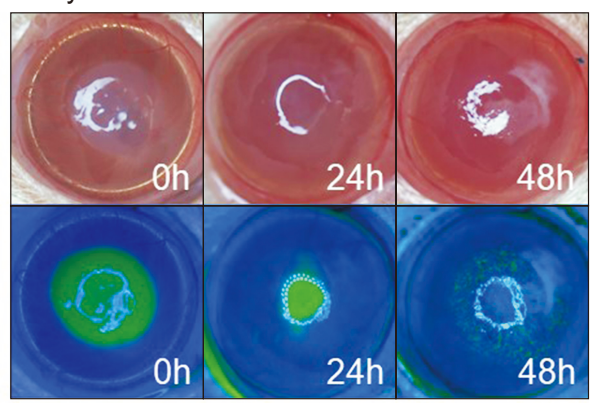

D Solcoseryl (gel)

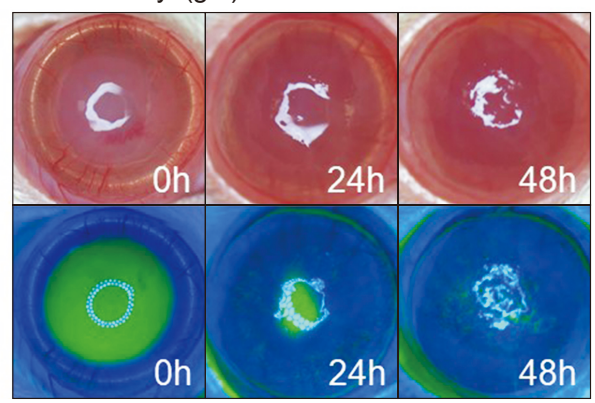

Fig. 1. Microscopic observations on corneal alkali burn wound healing in rat in vivo model. Bright field observation (above) and blue light observation (below) show similar wound healing rate in all experimental groups. There are almost no signs of wound at 48-hour period after giving alkali burn wounds. 


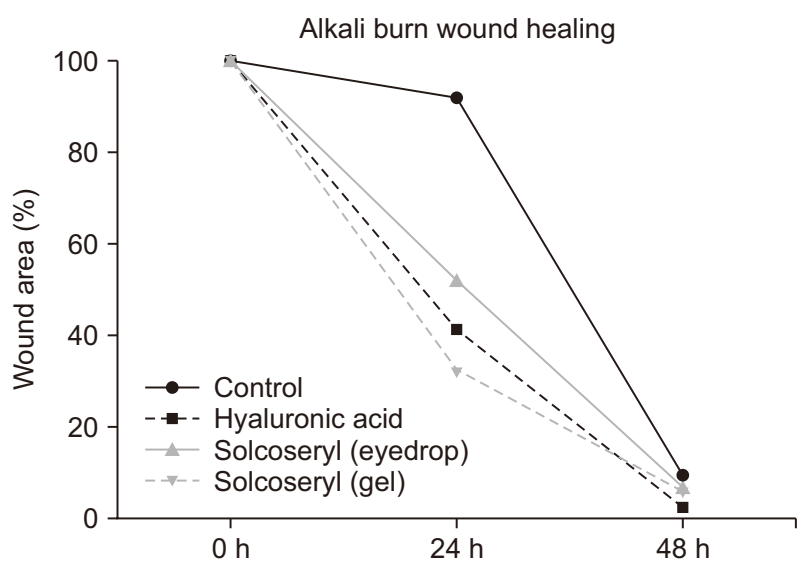

Fig. 2. Corneal alkali burn wound healing rate in rat in vivo model. Various treatments on corneal alkali burn showed that the differences were observed at 24-hour period after giving wounds. Solcoseryl gel had the highest healing rate among the other experimental groups, and hyaluronic acid treatment group had higher healing rate when compared to the Solcoseryl eyedrop group.

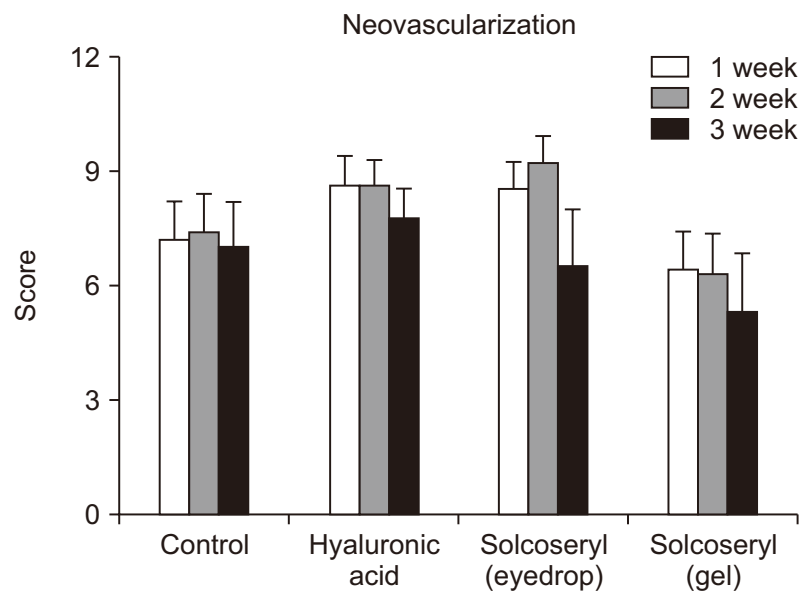

Fig. 3. Neovascularization scores of corneal alkali burn rat in vivo model. There were no significant differences in neovascularization scores among all the experiment groups but there still was a trend that Solcoseryl treatment lowered the degree of neovascularization when compared to the control and hyaluronic acid treatment groups.

uronic acid treatment group (Fig. 6). Also, the levels of inflammatory cytokines in cornea were lower in Solcoseryl treatment groups. However, no significant differences were observed among hyaluronic acid and Solcoseryl treatment groups.

Immunohistochemistry on retina confirmed that the inflammation caused on corneal tissue was spread to all the retinal layers (Fig. 7). When the number of inflammatory ganglion cells were count, the level of IL-1 13 was lower in all the treatment groups compared to the control $1 p<0.001$ in hyaluronic acid and Solcoseryl eyedrop treat-

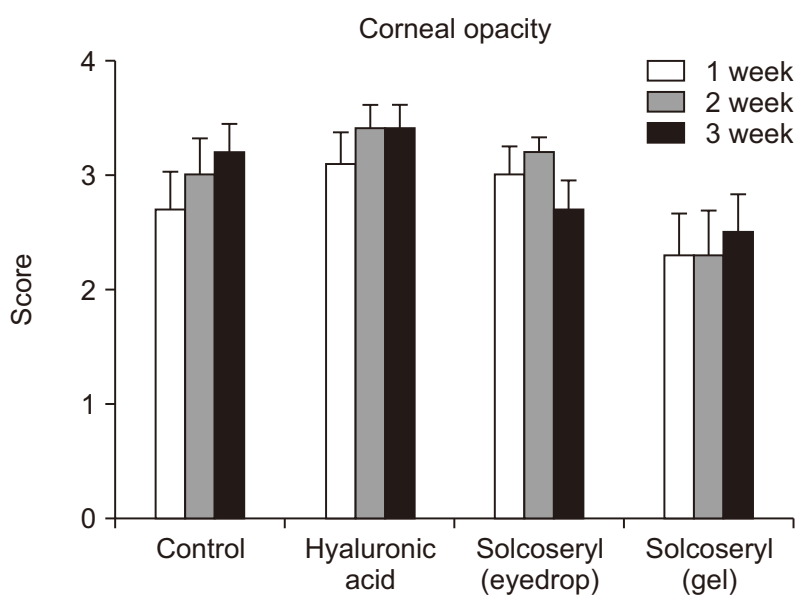

Fig. 4. Corneal opacity scores of corneal alkali burn rat in vivo model. There were no significant differences in corneal opacity scores among all the experiment groups but Solcoseryl treatment groups showed a tendency to have lower corneal opacity scores when compared to the control and hyaluronic acid treatment groups.

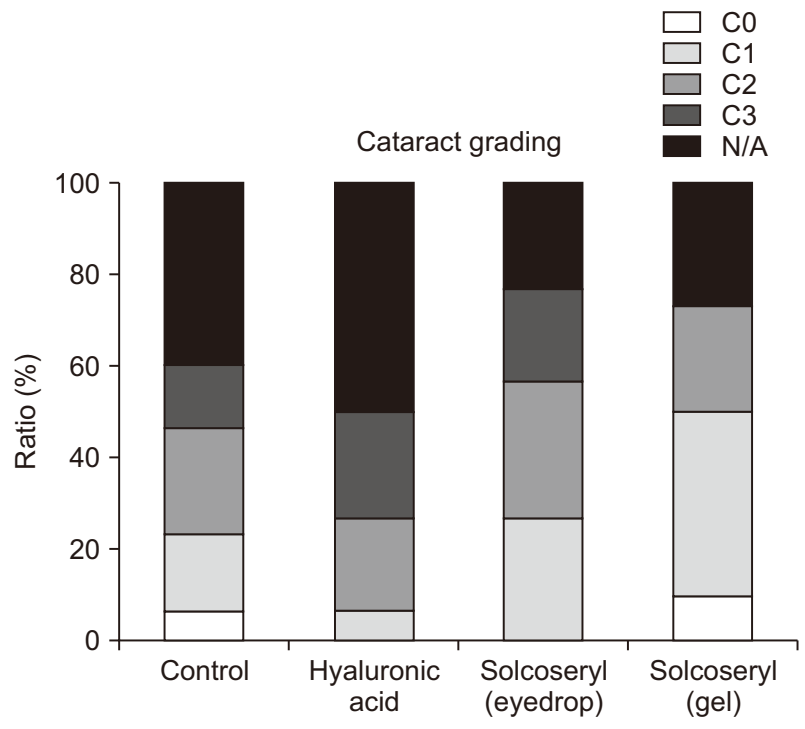

Fig. 5. Cataract gradings of corneal alkali burn rat in vivo model. Opaque corneas with iris not visible are labelled as "N/A". Solcoseryl treatment groups had lower grades compared to other experiment groups.

ment group; $p<0.01$ in Solcoseryl gel treatment group), IL- 6 and TNF- $\alpha$ were lower in hyaluronic acid $(p<0.05)$ and Solcoseryl gel $(p<0.01)$ treatment groups. Solcoseryl eyedrop treatment group showed similar IL-6 and TNF- $\alpha$ levels when compared to the control.

To observe any changes caused by corneal alkali burn on retinal tissues, the thickness of retina and each retinal layer were measured and compared (Fig. 8). The thickness of entire retina was $232.8 \pm 5.53 \mu \mathrm{m}$ in control group, 

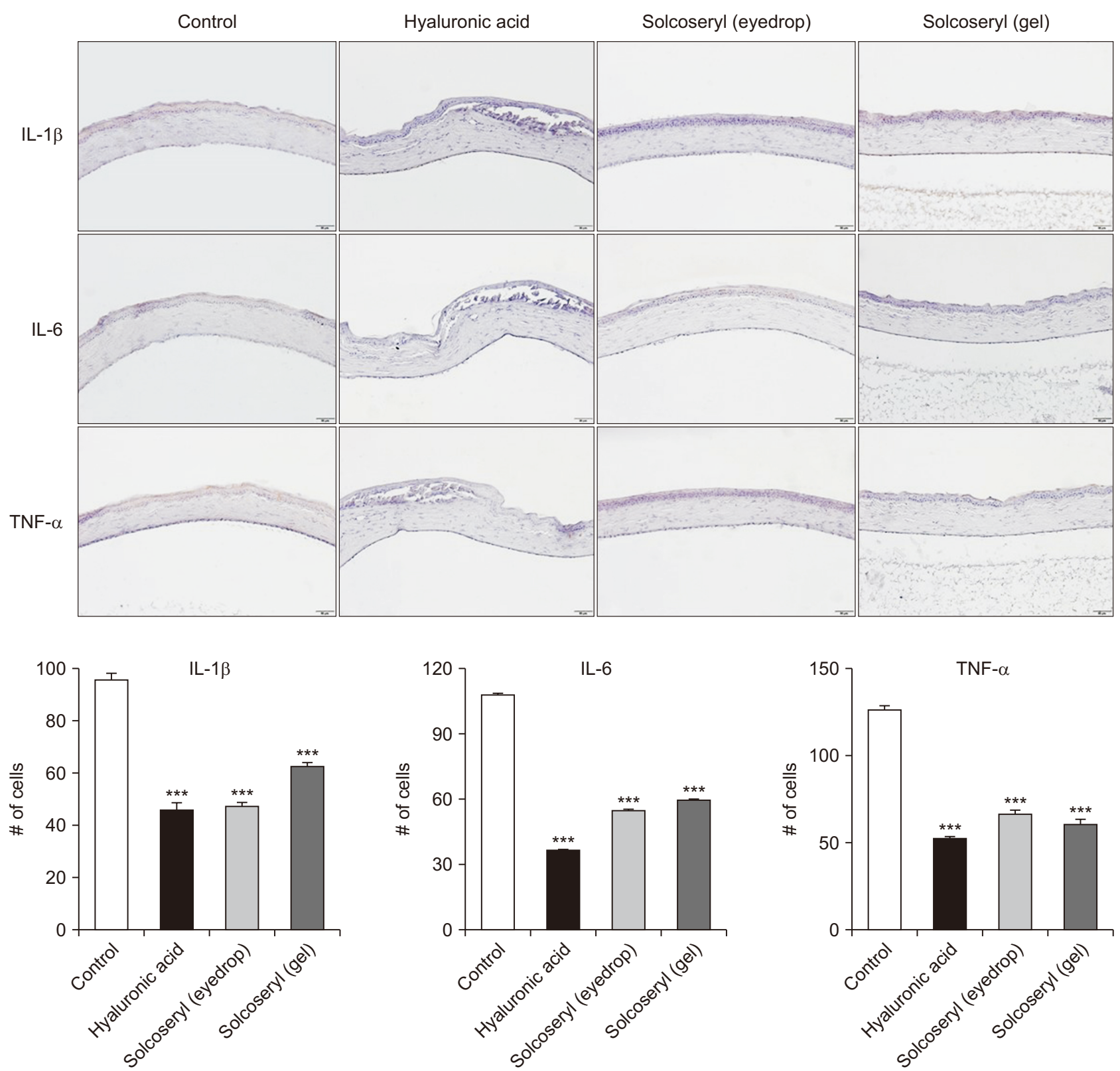

Fig. 6. Immunohistochemistry of cornea in corneal alkali burn rat model. IHC showed that corneal structures were stable in Solcoseryl treatment groups and the level of inflammatory cytokines were also lower in Solcoseryl treatment groups. However, there was no significant differences between hyaluronic acid treatment group.

while $216.3 \pm 2.99 \mu \mathrm{m}$ in hyaluronic acid treatment group, $239.5 \pm 4.43 \mu \mathrm{m}$ in Solcoseryl eyedrop treatment group, and $253.2 \pm 10.19 \mu \mathrm{m}$ in Solcoseryl gel treatment group, showing no significant differences in all groups. The thickness of inner limiting membrane (ILM) and ganglion cell layer (GCL) was $21.98 \pm 1.67 \mu \mathrm{m}$ in control, $25.05 \pm$ $0.92 \mu \mathrm{m}$ in hyaluronic acid treatment group, $25.96 \pm 1.35$ $\mu \mathrm{m}$ in Solcoseryl eyedrop treatment group, and $28.56 \pm$ $2.07 \mu \mathrm{m}$ in Solcoseryl gel treatment group, Solcoseryl gel treatment group being significantly higher than the control ( $p<0.05)$. The thickness of inner plexiform layer (IPL) was $57.19 \pm 1.99 \mu \mathrm{m}$ in control group, $74.97 \pm 2.27$ $\mu \mathrm{m}$ in hyaluronic acid treatment group, $67.94 \pm 2.19 \mu \mathrm{m}$ in Solcoseryl eyedrop treatment group, and $28.56 \pm 2.07$ $\mu \mathrm{m}$ in Solcoseryl gel treatment group, hyaluronic acid and Solcoseryl gel treatment groups being significantly higher than the control $(p<0.01)$. The thickness of inner nuclear layer (INL) was $33.57 \pm 1.04 \mu \mathrm{m}$ in control group, $34.66 \pm$ $0.81 \mu \mathrm{m}$ in hyaluronic acid treatment group, $43.99 \pm 1.32$ $\mu \mathrm{m}$ in Solcoseryl eyedrop treatment group, and $42.71 \pm$ 

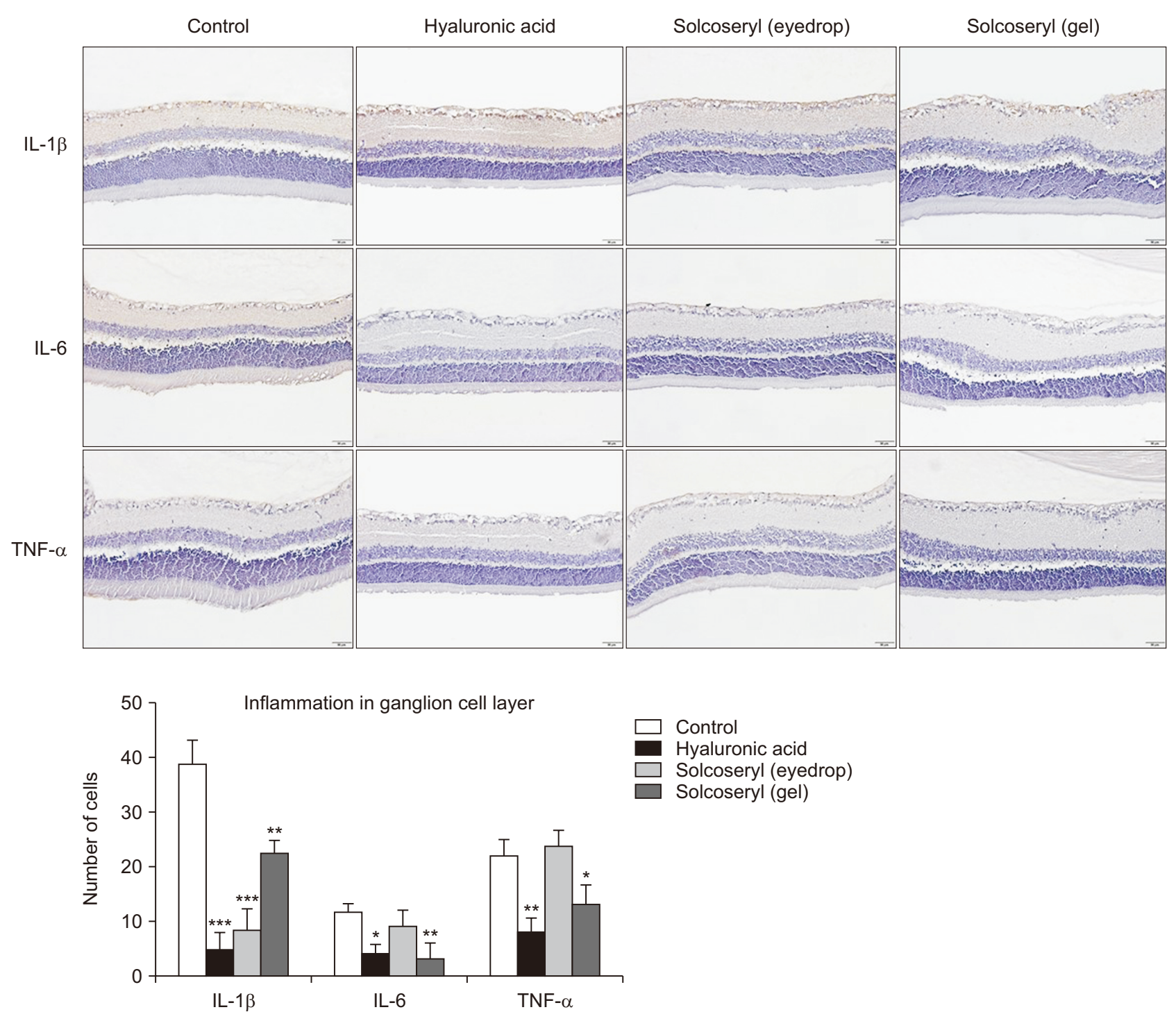

Fig. 7. Immunohistochemistry of retina in corneal alkali burn rat model. IHC showed that the inflammation caused in cornea were spread to retina. Hyaluronic acid and Solcoseryl treatments did not alleviate retinal inflammation.

2.47 $\mu \mathrm{m}$ in Solcoseryl gel treatment group, Solcoseryl gel treatment group being significantly higher than the control ( $p<0.01)$. The thickness of outer plexiform layer (OPL) was $13.34 \pm 0.56 \mu \mathrm{m}$ in control group, $9.92 \pm 0.69$ $\mu \mathrm{m}$ in hyaluronic acid treatment group, $11.58 \pm 0.57 \mu \mathrm{m}$ in Solcoseryl eyedrop treatment group, and $12.51 \pm 0.73$ $\mu \mathrm{m}$ in Solcoseryl gel treatment group, hyaluronic acid treatment group being significantly lower than the control $(p<0.01)$. The thickness of outer nuclear layer (ONL) was $73.41 \pm 2.64 \mu \mathrm{m}$ in control group, $51.94 \pm 1.74 \mu \mathrm{m}$ in hyaluronic acid treatment group, $57.26 \pm 0.99 \mu \mathrm{m}$ in Solcoseryl eyedrop treatment group, and $64.83 \pm 4.38 \mu \mathrm{m}$ in Solcoseryl gel treatment group, hyaluronic acid $(p<0.001)$ and Solcoseryl eyedrop $(p<0.01)$ treatment groups being significantly higher than the control.

\section{DISCUSSION}

Solcoseryl is being used in treating burns in various models including horse, ${ }^{8} \mathrm{dog}_{1}{ }^{9} \mathrm{rat}^{10,11} \mathrm{pig}^{12}$ and guineapig $^{13}$ both in vitro and in vivo, based on the previously reported studies regarding wound healing with minimal scarring ${ }^{4}$ and acceleration of healing burns and ulcers in human tissues. ${ }^{14,15}$

The current study revealed that applying Solcoseryl on corneal alkali burn not only accelerates wound healing rates in cornea but also prevents neovascularization and maintains corneal opacity. 

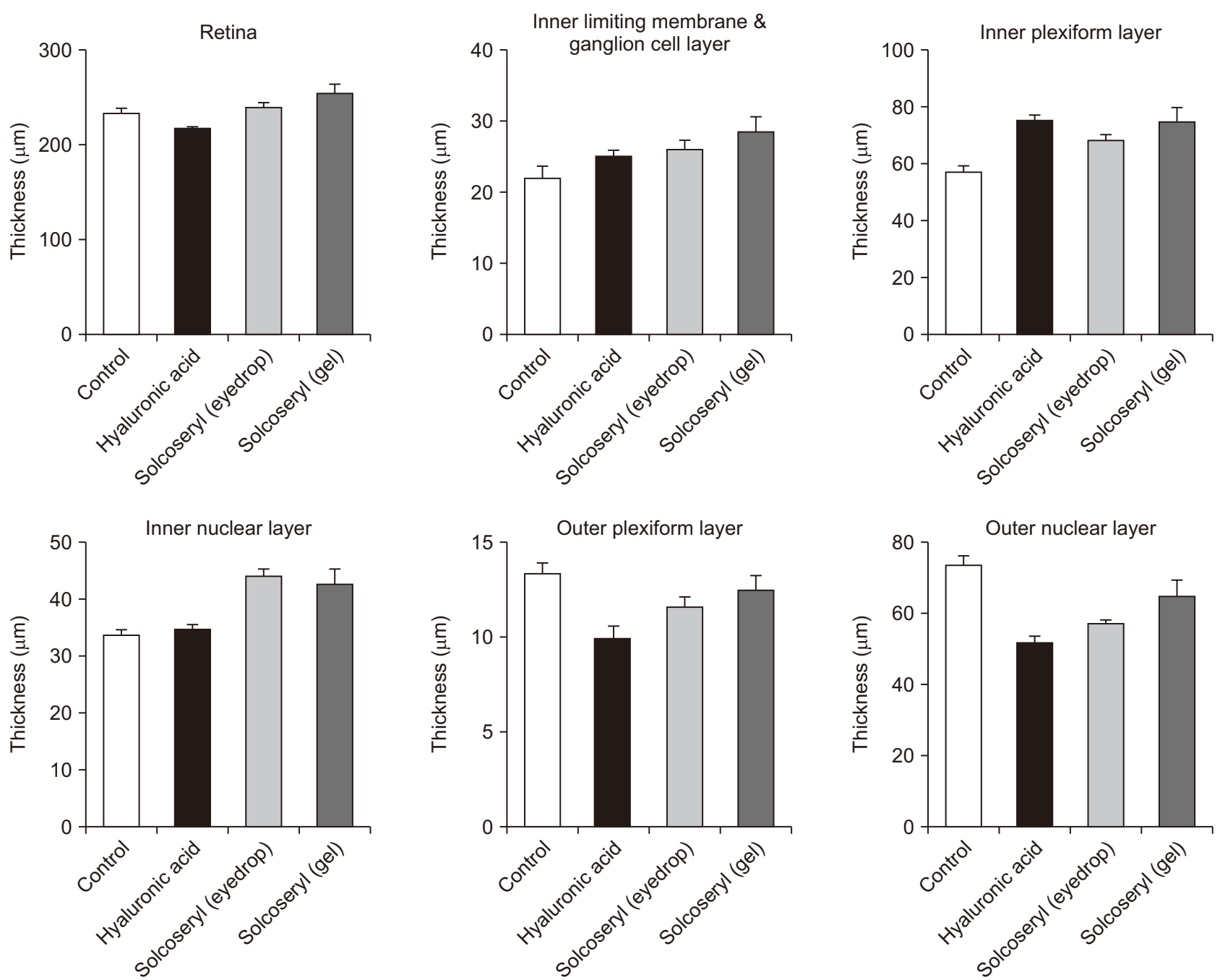

Fig. 8. Retinal layer thickness in corneal alkali burn rat model. Due to retinal inflammation the thickness of each retinal layer varied in the experimental groups.

Table 1. Comparison between the results of current study and previously reported studies

\begin{tabular}{lllll}
\hline & HA & SE & SG & \\
\hline Retina & $\downarrow$ & $\uparrow$ & $\uparrow$ & $\uparrow$ (Acute anterior uveitis) $^{21}$ \\
ILM/GCL & $\uparrow^{* *}$ & $\uparrow$ & $\uparrow^{*}$ & $\downarrow$ (Glaucoma/vision loss) $^{22}$ \\
IPL & $\uparrow^{* *}$ & $\uparrow^{* *}$ & $\downarrow$ (Glaucoma/vision loss) $^{22}$ \\
INL & $\uparrow^{* * *}$ & $\uparrow^{* *}$ & $\downarrow$ (Acute macular neuroretinopathy) $^{25}$ \\
OPL & $\downarrow^{* *}$ & $\downarrow$ & $\uparrow$ (Retinal degeneration / photoreceptor loss) $^{23}$ \\
ONL & $\downarrow^{* * *}$ & $\downarrow^{* *}$ & $\downarrow$ & $\uparrow$ (Acute macular neuroretinopathy) $^{25}$ \\
\hline
\end{tabular}

ILM, inner limiting membrane; GCL, ganglion cell layer; IPL, inner plexiform layer; INL, inner nuclear layer; OPL, outer plexiform layer; ONL, outer nuclear layer.

According to the in vitro studies on corneal epithelial cells, Solcoseryl aids wound healing in stimulating the secretion of various mucin proteins MUC1, MUC5AC, MUC7 and MUC16, and enhanced the activity of signaling factors Akt, FAK, ERK, and Src to regulate cellular migration, adhesion and proliferation. ${ }^{16}$ MUC1, MUC5AC secreted from 
corneal epithelial cells and conjunctival cells and MUC7 secreted from lacrimal gland contribute to tear film formation and prevent infections, ${ }^{17}$ while MUC16 produces barrier on corneal surface to block adhesion of foreign matter. ${ }^{18}$ Such enhancement in tear film may aid washing out of the excess alkaline agent after alkali burn.

Immunohistochemistry results also confirmed the effect of Solcoseryl in controlling inflammatory cytokines $\mathrm{IL}-1 \mathrm{~b}, \mathrm{IL}-6$, and TNF-a in all treatment groups. When comparing the two types of Solcoseryl, eyedrop was more effective in cornea, while gel was more effective in retina. This difference is thought to be caused by the physical traits of dosage forms. With the same ingredient and concentrations, the dosage form may also be a deciding factor in effective wound healing. Residence time on the ocular surface may be longer when applied as a gel compared to the eyedrop type. Some studies reported that topical ophthalmic drops dissipate almost completely after drop administration, and must also be applied frequently. ${ }^{19,20}$

However, applying Solcoseryl on corneal alkali burn did not prevent the spread of inflammation from cornea to retina. The results of current study showed that the thickness of retina was affected by corneal alkali burn and the treatments. Based on the previous studies reporting about the correlation between various retinal conditions and retinal layer thickness, the current study compared the thickness of each retinal layer (Table 1).

The thickness of entire retina was similar in all the groups, with a decrease in hyaluronic acid treatment group and increase in Solcoseryl gel treatment group. It was reported that the thickness of entire retina gets thickened with acute anterior uveitis, which implies the hyaluronic acid treatment reduced the degree of inflammation in retina while Solcoseryl treatment did not affect on retinal inflammation. ${ }^{21}$

When the thickness of each layer was compared, the thickness of GCL and ILM was increased in all treatment groups compared to the control, with significant difference in Solcoseryl gel treatment group $(p<0.05)$. Also, IPL thickness was increased in all treatment groups, with significant difference in hyaluronic acid and Solcoseryl gel treatment groups $(p<0.01)$. The $G C L$ and IPL thickness is known to be affected by glaucoma and vision loss to be decreased..$^{22}$ The results of current study did not show any of the reported symptoms and the inflammation caused by corneal alkali burn was alleviated by hyaluronic acid and Solcoseryl treatments.

The thickness of INL had a tendency to be thickened in all treatment groups compared to the control, with sig- nificant increase in Solcoseryl treatment groups. It has been known that macular degeneration and loss of photoreceptors occur with INL thickening, ${ }^{23}$ and the results of current study suggest that photoreceptors could have been affected by retinal inflammation and the hypertrophy of Muller glial cells increased the layer thickness. ${ }^{24}$

The thickness of OPL tended to decrease in all treatment groups, with significant difference in hyaluronic acid treatment group $(p<0.01)$. It has been reported that OPL thickness increases when acute macular neuroretinopathy occurs. ${ }^{23}$ Also, acute macular neuroretinopathy may affect the OPL thickness, causing thrombosis to disrupt deep capillary network and giving ischemic damage to the retina. ${ }^{25}$

The thickness of ONL decreased in all treatment groups with significant differences in hyaluronic acid treatment group $(p<0.001)$ and Solcoseryl gel treatment group $(p<0.01)$. It is known that the ONL thickness is affected by acute macular neuroretinopathy or macular degeneration to be decreased. ${ }^{23,25}$

In conclusion, this study revealed that there are advantages and disadvantages in applying hyaluronic acid and Solcoseryl on corneal alkali burn. Hyaluronic acid treatment may control the inflammatory reactions in cornea and retina, but also cause instability in corneal tissue. Solcoseryl treatment accelerates wound healing rate while maintaining tissue stability, but cannot prevent the spread of inflammation from cornea to retina. The effectiveness of eyedrop in cornea and gel in retina seem to be caused by the residual time in the tissues.

\section{CONFLICT OF INTEREST}

Kyong Jin Cho is an editorial board member of the journal but was not involved in the review process of this manuscript. Otherwise, there is no conflict of interest to declare.

\section{FUNDING}

This research was supported by Basic Science Research Program through the National Research Foundation of Korea (NRF) funded by the Ministry of Education (2019R1I1A3A0105910212).

\section{REFERENCES}

1. World Health Organization. World health statistics [Internet]. Geneva: World Health Organization; 2015. [cited 2020 Oct 20]. Available from: https://www.who.int/gho/publications/world_ 
health_statistics/2015/en/.

2. Whitcher JP, Srinivasan M, Upadhyay MP. Corneal blindness: a global perspective. Bull World Health Organ 2001;79:214-21.

3. Dua HS, King AJ, Joseph A. A new classification of ocular surface burns. Br J Ophthalmol 2001;85:1379-83.

4. Eissa AE, Zaki MM, Saeid S, Abdelsalam M, Ali HM, Moustafa $A A$, et al. In vitro evaluation of the efficacy of hemodialysate (Solcoseryl $($ ) ) as a wound healing agent in Nile tilapia (Oreochromis niloticus). Int J Vet Sci Med 2013;1:57-64.

5. Dana MR, Streilein JW. Loss and restoration of immune privilege in eyes with corneal neovascularization. Invest Ophthalmol Vis Sci 1996;37:2485-94.

6. Bai JQ, Qin HF, Zhao SH. Research on mouse model of grade II corneal alkali burn. Int J Ophthalmol 2016;9:487-90.

7. Goo H, Kim H, Ahn J, Cho K. Effects of low-level light therapy at $740 \mathrm{~nm}$ on dry eye disease in vivo. Med Lasers 2019;8:50-8.

8. Wilmink JM, Stolk PW, van Weeren PR, Barneveld A. The effectiveness of the haemodialysate Solcoseryl for second-intention wound healing in horses and ponies. J Vet Med A Physiol Pathol Clin Med 2000;47:311-20.

9. Jöchle W, Hamm D. Effects of a protein-free dialysate of calf blood (Solcoseryl $\mathrm{l}^{\mathrm{r}}$ (a) $^{\text {and }}$ and hexosylceramide fraction on experimental corneal lesions in dogs. Clin Res Regul Aff 1986;4:5973.

10. Isler H, Bauen A, Baschong W. Topical treatment of standardized burns with a protein-free haemodialysate. Burns 1991;17:93-7.

11. Isler H, Bauen A, Hubler M, Oberholzer M. Morphometric assessment of wound healing in rats treated with a protein-free haemodialysate. Burns 1991;17:99-103.

12. Krupp S, Nadjafi A. [The effect of Solcoseryl on wound heling in dwarf pigs]. Helv Chir Acta 1969;36:634-40. German.

13. Gupta A, Lakshmi V, Jain GK, Raghubir R. Wound healing in guinea pigs after topical application of starfish Pentaceraster regulus extract. J Wound Care 2008;17:441-4.

14. Biland L, Hürlimann F, Goor W, Körner WF, Kündig A, Madar G, et al. Treatment of venous ulcers. A multi-center randomized double-blind study. Vasa 1985;14:383-9.
15. Rossano C, Weiner M, Haigis E. Clinical, blood gas, and lactate changes in the course of the treatment of peripheral vascular disease with a hemodialysate. Arzneimittelforschung 1990;40:1195-200.

16. Nam SM, Maeng YS. Wound healing and mucin gene expression of human corneal epithelial cells treated with deproteinized extract of calf blood. Curr Eye Res 2019;44:1181-8.

17. Spurr-Michaud S, Argüeso P, Gipson I. Assay of mucins in human tear fluid. Exp Eye Res 2007;84:939-50.

18. Blalock TD, Spurr-Michaud SJ, Tisdale AS, Heimer SR, Gilmore MS, Ramesh V, et al. Functions of MUC16 in corneal epithelial cells. Invest Ophthalmol Vis Sci 2007:48:4509-18.

19. Ghate D, Edelhauser HF. Ocular drug delivery. Expert Opin Drug Deliv 2006;3:275-87.

20. Sultana Y, Jain R, Aqil M, Ali A. Review of ocular drug delivery. Curr Drug Deliv 2006;3:207-17.

21. Lee MW, Lee TH, Won YK, Shin YI, Kim JY. Characteristics of retinal layer thickness in acute anterior uveitis: an optical coherence tomography study. Acta Ophthalmol 2020;98:e50-5.

22. Kim EK, Park HL, Park CK. Relationship between retinal inner nuclear layer thickness and severity of visual field loss in glaucoma. Sci Rep 2017;7:5543.

23. Huang T, Wang Y, Zhang H, Gao N, Hu A. Limbal allografting from living-related donors to treat partial limbal deficiency secondary to ocular chemical burns. Arch Ophthalmol 2011;129:1267-73.

24. Bringmann A, landiev I, Pannicke T, Wurm A, Hollborn M, Wiedemann $P$, et al. Cellular signaling and factors involved in Müller cell gliosis: neuroprotective and detrimental effects. Prog Retin Eye Res 2009;28:423-51.

25. Munk MR, Beck M, Kolb S, Larsen M, Hamann S, Valmaggia C, et al. Quantification of retinal layer thickness changes in acute macular neuroretinopathy. Br J Ophthalmol 2017;101:160-5.

How to cite this article: Kim H, Kim HB, Seo JH, Lee DC, Cho KJ. Effect of solcoseryl in corneal alkali burn rat model. Med Lasers2021;10:22-30.https://doi.org/10.25289/ML.2021.10.1.22 